\title{
Gerenciamento em canteiros de obras: um estudo de caso na prefeitura de Sousa-PB
}

\author{
Management in construction sites: a case study in the city of Sousa-PB \\ Gestión en obras de construcción: un estudio de caso en la ciudad de Sousa-PB
}

Recebido: 10/11/2021 | Revisado: 19/11/2021 | Aceito: 23/11/2021 | Publicado: 05/12/2021

Thalles José Mesquita Silveira ORCID: https://orcid.org/0000-0002-8386-4220 Faculdade Santa Maria, Brasil E-mail: thalles1906@gmail.com

Elysson Marcks Gonçalves Andrade ORCID: https://orcid.org/0000-0001-7392-3736 Faculdade Santa Maria, Brasil E-mail: marcksagro@gmail.com

Hellykan Berliet dos Santos Monteiro ORCID: https://orcid.org/0000-0002-1294-3853 Faculdade Santa Maria, Brasil E-mail: hellykan@hotmail.com

Guilherme Urquisa Leite ORCID: https://orcid.org/0000-0002-8537-8496 Faculdade Santa Maria, Brasil E-mail: guilhermeurquisa@hotmail.com

Michael Douglas Sousa Leite

ORCID: https://orcid.org/0000-0002-9356-1872

Faculdade Católica Santa Teresinha, Brasil

E-mail: michaeldouglas_adm@hotmail.com

\begin{abstract}
Resumo
O ramo construção civil é uma área que compreende uma quantidade grande de variáveis, sendo desenvolvida em um ambiente mutável e dinâmico, o que faz o gerenciamento de uma obra/construção um trabalho extremamente complexo. Nesse sentido, o objetivo deste estudo é analisar os processos produtivos em um canteiro de obras em um Município do Interior da Paraíba. Para alcançar os objetivos do trabalho, foi efetuado um estudo de caso, quantiqualitativo, com procedimento descritivo. A referida obra foi uma obra de necessidade, visto que o terminal rodoviário se encontrava com uma demanda alta de serviços, tendo sua com sua capacidade produtiva restrita devido a seu precário estado estrutural para funcionamento. Os dados foram coletados através de um checklist, sendo baseado nos estudos de Amorim (2018) que analisou o planejamento e o processo produtivo em um canteiro de obras. Os resultados mostraram que o canteiro de obra pesquisado pode ser classificado com resultados regular acerca das "Instalações Provisórias" e ruins na "Segurança", e "Movimentação e Armazenamento de materiais". Tais problemas detectados têm negativo impacto, principalmente nos processos produtivos, ao impedir que a organização melhore seus indicadores de produtividade e sua competitividade. Dentre dos pontos a serem melhorados os resultados mostraram a questão do lixo, armazenagem de maneira incorreta, a falta de uso de EPI e as questões relacionadas à segurança e saúde dos colaboradores.
\end{abstract}

Palavras-chave: Construção civil; Obras públicas; Planejamento; Produção.

\begin{abstract}
The construction industry is an area that comprises a large number of variables, being developed in a changing and dynamic environment, which makes managing a work/construction an extremely complex job. In this sense, the aim of this study is to analyze the production processes in a construction site in a municipality in the interior of Paraíba. To achieve the objectives of the work, a case study was carried out, quantitative and qualitative, with a descriptive procedure. The referred work was a work of necessity, since the bus terminal had a high demand for services, having its production capacity restricted due to its precarious structural state for operation. Data were collected through a checklist, based on studies by Amorim (2018) who analyzed the planning and production process at a construction site. The results showed that the researched construction site can be classified with regular results regarding "Provisional Facilities" and poor in "Security", and "Material Handling and Storage". Such detected problems have a negative impact, mainly on production processes, by preventing the organization from improving its productivity and competitiveness indicators. Among the points to be improved, the results showed the issue of garbage, incorrect storage, the lack of use of PPE and issues related to the safety and health of employees.
\end{abstract}

Keywords: Construction; Public works; Planning; Production. 


\begin{abstract}
Resumen
La industria de la construcción es un área que comprende una gran cantidad de variables, desarrollándose en un entorno cambiante y dinámico, lo que hace que la gestión de una obra / construcción sea un trabajo sumamente complejo. En este sentido, el objetivo de este estudio es analizar los procesos productivos en una obra de construcción en un municipio del interior de Paraíba. Para lograr los objetivos del trabajo se realizó un estudio de caso, cuantitativo y cualitativo, con un procedimiento descriptivo. La mencionada obra fue una obra de necesidad, ya que la terminal de buses tenía una alta demanda de servicios, y su capacidad de producción estaba restringida debido a su precario estado estructural para su funcionamiento. Los datos se recopilaron a través de una lista de verificación, basada en estudios de Amorim (2018), quien analizó el proceso de planificación y producción en un sitio de construcción. Los resultados mostraron que el sitio de construcción investigado puede clasificarse con resultados regulares en cuanto a "Instalaciones provisionales" y deficientes en "Seguridad" y "Manejo y almacenamiento de materiales". Los problemas detectados tienen un impacto negativo, principalmente en los procesos productivos, al impedir que la organización mejore sus indicadores de productividad y competitividad. Entre los puntos a mejorar, los resultados mostraron el tema de la basura, el almacenamiento incorrecto, la falta de uso de EPI y cuestiones relacionadas con la seguridad y salud de los empleados. Palabras clave: Construcción civil; Obras públicas; Planificación; Producción.
\end{abstract}

\title{
1. Introdução
}

A construção civil é uma área que compreende uma grande quantidade de variáveis, sendo desenvolvida em um ambiente mutável e dinâmico como é destacado nos estudos de (Ribeiro, 2011; Mattos, 2010; Amorin, 2018), o que faz o gerenciamento de uma obra um trabalho extremamente complexo, pois o trabalho desse setor requer uma grande responsabilidade (Mattos, 2010).

No contexto brasileiro, muitas obras públicas ainda são mal executadas, ou seja, sem qualquer planejamento e sem nenhuma garantia do cumprimento do orçamento e prazo previamente estabelecidos (Altounian, 2012). De acordo com Hamzeh, Ballard e Tommelein (2011), as deficiências no controle e planejamento em especial sobre o canteiro de obras, estão entre as causas principais da baixa produtividade do setor de construção civil, de suas perdas elevadas e da baixa qualidade das obras. Nesse sentido, um planejamento correto é fundamental para melhorar a produtividade e reduzindo possíveis atrasos, apresentando a sequência correta de produção, balanceando as necessidades de mão de obra para o trabalho e coordenando as múltiplas atividades interdependentes.

Fica claro que funcionalidade e qualidade de um canteiro de obras são as características principais esperadas em uma construção, especialmente quando se trata de obra pública, contudo isso não ocorre (Silveira Júnior \& Gregório, 2015). A administração pública municipal encontra muitas dificuldades em gerir e atender a todos requisitos desejados em tais obras, que além de funcionalidade e qualidade, abrangem os prazos e relação do custo/benefício (Perez, 2011; Custódio \& Tomim, 2016).

Colaborando com as falas acima Magalhães, Mello e Bandeira (2018) preconizam que o planejamento sem levar em conta a definição dos métodos estimativas de recursos, de produção, cálculo da capacidade de produção e emprego de indicadores de produtividade geram planos inexecutáveis. Por sua vez, Souza e Monteiro (2011) destacam que a falta de adoção de metodologias que buscam proteger a produção gerara descontinuidade no processo e o não cumprimento de prazos.

$\mathrm{Na}$ vivencia do canteiro de obras, é importante que o planejamento e controle atenda a todas condições precisas para encaixar de maneira correta a rotina de atividades, sendo importante esquematizar e implementar o andamento de armazenagem e distribuição de todo o material da obra. Neste cenário, que o planejamento e controle na construção civil, torna-se essencial, já que imprevistos podem ocorrer e em seguida, gastos não programados (Araújo; Souza \& Silva, 2019).

Para tanto, as empresas do ramo de construção civil procuram formas de melhorar seus processos produtivos e gerenciais. A procura pela informação desses processos propendendo sua implementação, tem como finalidade a melhoria dos seus produtos finais e com natural acréscimo na agregação de valor de seu produto ao cliente (Romanel, 2017).

Assim, o gerenciamento da qualidade e da produtividade na construção civil, mostra situações que as vezes demonstram ceticismo no meio organizacional. A utilização de sistemas de Produção e Controle de Produção são sem nenhuma dúvida ainda é uma variável a ser trabalhado por todos que trabalham na área. Deste modo, procura-se mostrar que o ramo de construção civil 
deve estar atenta às mudanças organizacionais e de mercado com a finalidade de trazer melhorias sejam elas de consumo, ambientais ou de custos (Gomes, 2015).

Amorim e Rocha (2012) afirmam que as organizações precisam dedicar-se ao aprimoramento dos processos que podem trazer-lhes melhorias, visto que são esses que podem garantir a sua permanência no mercado. Os autores destacam ainda que a melhoria é um dos fatores que determinam os lucros, pois ajudará a amortecer os desperdícios, seja ao longo do processo produtivo ou no produto final.

O presente artigo busca analisar os processos produtivos em um canteiro de obras na Prefeitura de Sousa-PB com isso busca-se estudar os meios que facilitam a execução e aumentam a produtividade das obras públicas na cidade, dando uma maior eficiência as obras públicas.

\section{Metodologia}

A presente pesquisa em questão trata-se de um estudo de caso, quantiqualitativo, com procedimento descritivo.

O estudo foi realizado na cidade de Sousa - PB, Latitude: -6.76782, Longitude: -38.2099 6 $6^{\circ} 46^{\prime} 4^{\prime \prime}$ Sul, $38^{\circ} 12^{\prime} 36^{\prime \prime}$ Oeste, a referida cidade ocupa uma área de $738,547 \mathrm{~km}^{2}$; soma uma população 68.434 habitantes, sendo o sexto município mais populoso do estado, o primeiro de sua microrregião (Microrregião de Sousa) e o segundo de sua mesorregião (Mesorregião do Sertão Paraibano); e localiza-se à oeste da capital do estado (João Pessoa), distante desta cerca de 438 km (IBGE, 2010).

Os dados foram coletados através de uma lista de verificações estruturado formulado com itens objetivos pertinentes à proposta de estudo. O trabalho foi baseado nos estudos de Amorim (2018) que analisou o planejamento e o processo produtivo em um canteiro de obras por meio de uma lista de verificações.

Com isso, o canteiro em estudo foi na Rodoviária Adilmar de Paiva Gadelha, sendo analisado as seguintes etapas: Preenchimento da lista de verificação; Desenho de croquis do layout do canteiro; Registro fotográfico; Análise dos canteiros, apontamentos dos problemas e Apresentação de soluções.

A visita ao canteiro de obras foi realizada no mês de setembro de 2021, com a finalidade de analisar o layout das instalações, colocar em execução a teoria estudada e a metodologia adotada para realização desse trabalho. Durante a visita técnica foram coletadas informações, o desenho do croqui do canteiro, o preenchimento da lista de verificação e levantamento fotográfico da área.

A lista de verificações é uma etapa mais abrangente, pois através dela pode ser feita uma análise qualitativa do canteiro, no que diz respeito a logística e layout, segundo os três principais aspectos: instalações provisórias, segurança no trabalho e sistema de movimentação e armazenamento de materiais. Todos os elementos devem ter um padrão mínimo de qualidade para o desempenho satisfatório de suas funções.

A forma de análise foi objetiva e visual da sua existência ou não, dispensando medições. O intuito da análise foi para saber se algum espaço é necessário e não existe no canteiro, assim como verificar sua localização e, até mesmo, atribuir nota para os espaços existentes.

Por fim foram realizados registros fotográficos que complementaram as etapas apresentadas anteriormente, foram registros visuais da situação encontrada, com o intuito de verificar se existem problemas e buscar soluções apropriadas para cada caso

\section{Resultados e Discussão}

O canteiro de Obras está localizado na Rua José Fagundes de Líra, 300 - Gato Preto, Sousa - PB e foi uma obra de necessidade, visto que o referido terminal se encontrava com uma demanda alta de serviços, tendo sua capacidade produtiva restrita devido a seu precário estado estrutural para funcionamento. As instalações apresentavam um mal estado de conservação 
e deterioração devido ao mal uso e ação do tempo. Destarte, ficou claro a importância dessa reforma para esta cidade.

Observa-se na Figura 1, desenho do Layout de parte do canteiro de obras em estudo.

Figura 1 - Desenho do Layout do canteiro de Obras da Rodoviária Adilmar de Paiva Gadelha.

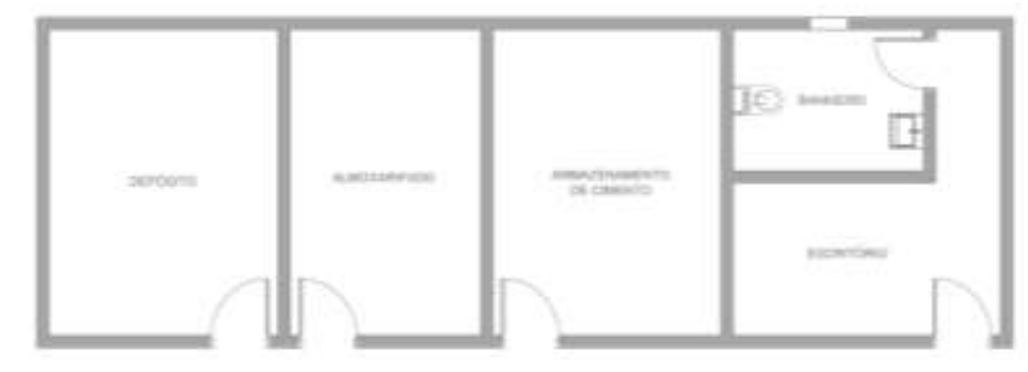

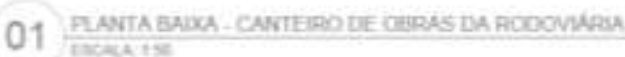

Fonte: Dados da Pesquisa (2021).

A planta baixa apresenta uma ideia geral das instalações com o escritório para os responsáveis técnicos, com mesas e cadeiras, um banheiro para uso dos colaboradores, um local para o armazenamento do cimento, o almoxarifado e por último um deposito para guardar as ferramentas de trabalho. A referida obra foi orçada em 1,1 milhão de reais e previsão de entrega era para o dia 15 de julho de 2021, contudo foi adiada e a nova previsão de entrega da obra foi para em 02 de janeiro de 2021, já estamos terminando o ano de 2021 e ainda não foi finalizada.

A Figura 2 abaixo apresenta a obra ainda inacabada e sem previsão de termino.

Figura 2 - Foto do canteiro de Obras da Rodoviária Adilmar de Paiva Gadelha.

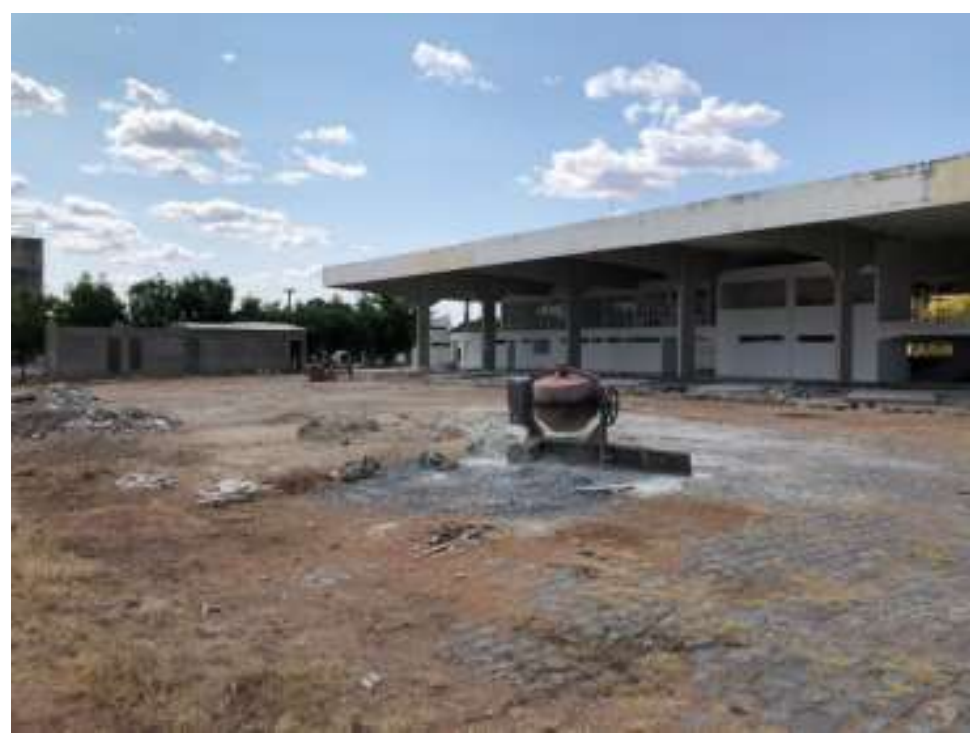

Fonte: Dados da Pesquisa (2021).

A referida obra encontra com problemas na justiça devido à demora na entrega do serviço realizado pela Prefeitura, e além disso, existem denúncias envolvendo corrupção. Segundo dados vinculados a impressa local o Ministério Público da Paraíba apura possíveis irregularidades na obra do Terminal Rodoviário de Sousa - PB, após denúncias sobre a demora na entrega do serviço realizado pela Prefeitura local. 
No Quadro 1, destaca-se a lista de verificações, que é um modelo adaptado de Amorin (2018), e foi construída com o intuito de verificar a logística e o layout, segundo os três principais aspectos: as instalações provisórias, a segurança no trabalho e o sistema de movimentação e de armazenamento de materiais. A lista apresenta a existência ou não dos itens necessários para o funcionamento do projeto, assim como o padrão mínimo de qualidade no canteiro.

Quadro 1 - Lista de verificações do canteiro de Obras Analisado.

\begin{tabular}{|c|c|c|c|}
\hline A) INSTALAÇÕES PROVISÓRIAS & Sim & Não & $\begin{array}{l}\text { Não se } \\
\text { aplica }\end{array}$ \\
\hline \multicolumn{4}{|l|}{ A.1) TIPOLOGIA DAS INSTALAÇÕES PROVISÓRIAS } \\
\hline São usadas instalações do tipo móvel (containers) & & $\mathrm{x}$ & \\
\hline A1.1) Há modulações em barracos & & $\mathrm{x}$ & \\
\hline A1.2) Os painéis usados são fáceis de instalar & & & $\mathrm{x}$ \\
\hline A1.3) Os painéis usados são pintados e estão em estado de conservação adequado & & & $\mathrm{x}$ \\
\hline A1.4) Foram usados materiais vindos de outras instalações & & $\mathrm{x}$ & \\
\hline A1.5) Os barracos usados estão localizados em locais livres de quedas & $\mathrm{x}$ & & \\
\hline A2) TAPUMES & & & $\mathrm{x}$ \\
\hline A3.1) Existe um portão designado para o acesso dos clientes e visitantes & & $\mathrm{x}$ & \\
\hline A3.2) Existe um caminho pavimentado para o acesso de veículos e de pessoas & $\mathrm{x}$ & & \\
\hline A3.3) Existe a possibilidade de entrar caminhões no canteiro & $\mathrm{x}$ & & \\
\hline A4) ESCRITÓRIO & & $\mathrm{x}$ & \\
\hline A4.1) Possui chaveiro com todas as chaves das instalações & $\mathrm{x}$ & & \\
\hline A4.2) A documentação da obra é algo de fácil acesso & $\mathrm{x}$ & & \\
\hline A4.3) Tem materiais de primeiro socorro & & $\mathrm{x}$ & \\
\hline \multicolumn{4}{|l|}{ A5) ALMOXARIFADO } \\
\hline A5.1) Está próximo do ponto da descarga dos caminhões & $\mathrm{x}$ & & \\
\hline A5.2) Existe etiqueta com nome dos materiais & & $\mathrm{x}$ & \\
\hline A5.3) É dividido em 02 ambientes, (materiais e ferramentas) e outro para o almoxarifado & & $\mathrm{x}$ & \\
\hline A5.4) Existem planilhas com controle de estoque e materiais & & $\mathrm{x}$ & \\
\hline A.6) LOCAL PARA REFEIÇÕES & & $\mathrm{x}$ & \\
\hline A6.1) Há um lavatório instalado nas suas proximidades ou em seu interior (NR-18) & & $\mathrm{x}$ & \\
\hline A6.2) Tem porta que permite o isolamento na hora das refeições (NR18) & & & $\mathrm{x}$ \\
\hline A6.3) Tem o piso de concreto, cimentado ou material que pode ser lavado (NR 18) & & & $\mathrm{x}$ \\
\hline A6.4) Tem o depósito com uma tampa para detritos (NR 18) & & & $\mathrm{x}$ \\
\hline A6.5) Há acentos com número correto para atender todos usuários (NR 18) & & & $\mathrm{x}$ \\
\hline A6.6) As mesas estão separadas para que os funcionários se agrupem conforme sua vontade & & & $\mathrm{x}$ \\
\hline A7) VESTIÁRIO & & & $\mathrm{x}$ \\
\hline A7.1) Tem o piso de concreto & & & $\mathrm{x}$ \\
\hline A7.2) Tem o banco e cabide & & & $\mathrm{x}$ \\
\hline A7.3) Tem o armário individuais com fechadura (NR 18) & & & $\mathrm{x}$ \\
\hline A8) INSTALAÇÕES SANITÁRIAS & $\mathrm{x}$ & & \\
\hline A8.1) Os banheiros usados estão próximos dos dormitórios & & & $\mathrm{x}$ \\
\hline A8.2) O mictório e lavatório são passiveis de reaproveitamento & $\mathrm{x}$ & & \\
\hline A8.3) Existem banheiros volantes próximo aos locais de trabalho (NR 18) & & $\mathrm{x}$ & \\
\hline A8.4) Há papel higiénico e os recipientes para o depósito dos papéis utilizados & & $\mathrm{x}$ & \\
\hline A8.5) Nos locais que estão os chuveiros existe piso antiderrapante & & & $\mathrm{x}$ \\
\hline A8.6) Há suporte para os sabonete e cabide para toalha & & & $\mathrm{x}$ \\
\hline A8.7) Existe banheiro exclusivo para colaboradores que cuida da administração da obra & & $\mathrm{x}$ & \\
\hline $\begin{array}{l}\text { A8.8) Para se deslocar do posto de trabalho até as instalações sanitárias é preciso percorrer menos de } 150,0 \\
\text { metros (NR 18) }\end{array}$ & $\mathrm{x}$ & & \\
\hline $\begin{array}{l}\text { A8.9) As paredes da parte inferior dos locais onde estão os chuveiros, são de alvenaria ou revestidas com } \\
\text { material impermeável. }\end{array}$ & & & $\mathrm{x}$ \\
\hline A9) ÁREAS DE LAZER & & & $\mathrm{x}$ \\
\hline A9.1) Existe local enquanto área para lazer, possuindo uma televisão ou jogos & & & $\mathrm{x}$ \\
\hline A10) LAVANDERIA & $\mathrm{x}$ & & \\
\hline A10.1) A lavanderia possui tanques coletivos ou individuais & & & $\mathrm{x}$ \\
\hline \multicolumn{4}{|l|}{ B) SEGURANÇA NA OBRA (FORMA GERAL) } \\
\hline B1) ESCADAS & & $\mathrm{x}$ & \\
\hline B1.1) Há corrimão provisório construído de madeira ou de outro material de resistência equivalente & & $\mathrm{x}$ & \\
\hline B1.2) Há escada ou rampa provisória para transposição de pisos com desnível superior à 40cm (NR 18) & & $\mathrm{x}$ & \\
\hline
\end{tabular}


B1.3) Os corrimãos estão pintados e estão com bom estado de uso

B.2) ESCADAS DE MÃO

B2.1) As escadas de mão ultrapassam em cerca de $1,0 \mathrm{~m}$ o piso superior

B2.2) As escadas de mão estão fixadas nos pisos superior e inferior, ou são dotadas de dispositivo que impeça escorregamento

B3) SINALIZAÇÃO DE SEGURANÇA

B3.1) Há identificação correta dos locais de apoio (banheiro, escritório, almoxarifado, etc.)

B3.2) Há alerta quanto a obrigatoriedade do uso do EPI, específico para atividade executada, próximo aos postos de trabalho (NR 18)

B3.3) Existe uma identificação de andares da obra

B3.4) Há advertências para o isolamento das áreas que são de transporte e de circulação de materiais por guincho, grua e guindaste

B3.5) Há placa no elevador de materiais, indicando o peso máxima e a proibição do transporte de pessoas (NR 18)

\section{B4) EPI'S}

B4.1) São fornecidos capacetes para visitantes

B4.2) Independente das funções todo os trabalhadores estão usando botina e capacete

B4.3) Os trabalhadores usam uniforme concedido pela empresa

B4.4) Trabalhadores em andaime externo ou qualquer outro tipo de serviço à mais de 2,0 $\mathrm{m}$ de altura, usam o cinto de segurança com os cabos fixados na construção (NR 18)

B5) INSTALAÇÕES ELÉTRICAS

B5.1) Circuitos e os equipamentos não têm partes vivas expostas, tais como: fios desencapados

B5.2) Os fios com energia estão em locais livres de trânsito de pessoas e de equipamentos, de maneira a preservar sua isolação (NR 18)

B5.3) Todas as máquinas/equipamentos elétricos estão ligados por um conjunto plugue e de tomada

B5.4) As redes que são de alta tensão estão protegidas de maneira a evitar contato acidentais com os veículos, trabalhadores e equipamentos (NR 18)

B5.5) Junto a todos os disjuntores existem identificações do circuito/equipamentos correspondentes

B6) PROTEÇÃO CONTRA INCÊNDIO

B6.1) O canteiro possui extintor de incêndio

B7) GUINCHO

B8) GRUA

C)SISTEMA DE MOVIMENTAÇÃO E ARMAZENAMENTO DE MATERIAIS

C1) VIAS DE CIRCULAÇÃO

C1.1) Há contrapiso em áreas de circulação de pessoas/materiais

C1.2) Existe uma cobertura para o transporte de materiais da betoneira até guincho

C1.3) É permitido o trânsito de carrinhos/jericas perto dos estoques em que tais equipamentos se fazem necessários

C1.4) Há caminhos previamente definidos para os principais fluxos de materiais, próximo ao guincho, e nas áreas de produção de argamassa e armazenamento.

C2) ENTULHO

C2.1) São utilizadas caixas para desperdícios nos andares e ou/depósito central de desperdícios

C2.2) O entulho é transportado para térreo por meio de tubo coletor ou calha

C2.3) O canteiro está limpo, sem a caliça e sobras de madeira, de maneira que não prejudicada a segurança e a circulação de materiais/pessoas

C2.4) O entulho é separado pelo tipo de material e depois reaproveitado.

C3) GUINCHO

\section{C4) ARMAZENAMENTO DE MATERIAIS}

CIMENTO

C4.1) Existe estrado sob o estoque de cimento

C4.2) As pilhas de cimento têm no máximo 10 sacos

C4.3) Os estoques estão protegidos da umidade em depósito coberto e fechado

C4.4) É usado a estocagem do tipo PEPS (Primeiro saco a entrar é o primeiro saco a sair), utilizando, a marcação da data de entrega em cada saco

C4.5) No caso de as pilhas estarem adjacentes as paredes (do depósito ou não) há uma distância mínima de 0,30 $\mathrm{m}$ para permitir a circulação de ar Obs.: O cimento é armazenado em um silo, apenas pequenos volumes é armazenado em paletes, em depósito próprio

AGREGADOS E ARGAMASSA

C4.6) As baias para areia, brita, argamassa têm contenção em 03 lados.

C4.7) As baias têm fundo cimentado buscando evitar a contaminação dos estoques.

C4.8) A areia é descarregada em local definitivo de armazenagem (não havendo duplo manuseio)

C4.9) A argamassa é descarregada em local definitivo de armazenagem (não havendo duplo manuseio)

\begin{tabular}{|c|c|c|}
\hline & $\mathrm{x}$ & \\
\hline & & $\mathrm{x}$ \\
\hline & & $\mathrm{X}$ \\
\hline & & $\mathrm{X}$ \\
\hline & $\mathrm{X}$ & \\
\hline & $\mathrm{X}$ & \\
\hline & $\mathrm{x}$ & \\
\hline & $\mathrm{x}$ & \\
\hline & $\mathrm{X}$ & \\
\hline & & $\mathrm{X}$ \\
\hline & $\mathrm{X}$ & \\
\hline & $\mathrm{x}$ & \\
\hline & $\mathrm{X}$ & \\
\hline $\mathrm{X}$ & & \\
\hline & $\mathrm{X}$ & \\
\hline $\mathrm{x}$ & & \\
\hline $\mathrm{X}$ & & \\
\hline $\mathrm{x}$ & & \\
\hline $\mathrm{X}$ & & \\
\hline $\mathrm{x}$ & & \\
\hline $\mathrm{X}$ & & \\
\hline & $\mathrm{x}$ & \\
\hline & $\mathrm{x}$ & \\
\hline & $\mathrm{x}$ & \\
\hline & $\mathrm{x}$ & \\
\hline
\end{tabular}

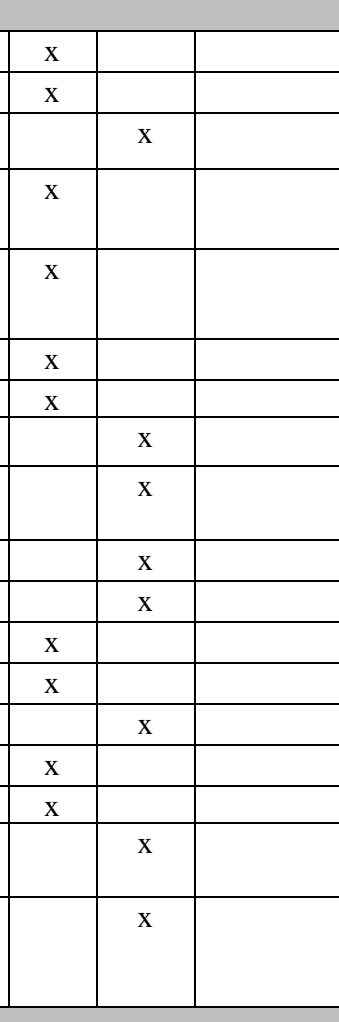




\begin{tabular}{|c|c|c|c|}
\hline $\begin{array}{l}\text { C4.10) As baias de areia e de argamassa estão em locais que são protegidos da chuva ou tem uma cobertura } \\
\text { com a lona }\end{array}$ & & $\mathrm{x}$ & \\
\hline C4.11) As baias de areia e de argamassa estão próximas da betoneira & & $\mathrm{x}$ & \\
\hline TIJOLOS/BLOCOS x AÇO & $\mathrm{x}$ & & \\
\hline $\begin{array}{l}\text { C4.12) O aço é protegido do contato direto com solo, sendo armazenados sobre pontaletes de madeiras e com } \\
\text { camada de brita }\end{array}$ & $\mathrm{x}$ & & \\
\hline C4.13) Caso barras estejam em local que seja descoberto, existe cobertura com a lona & & & $\mathrm{x}$ \\
\hline C4.14) As barras de aço são separadas e também identificadas segundo a bitola (NR 18) & & $\mathrm{x}$ & \\
\hline TUBULAÇÕES & $\mathrm{x}$ & & \\
\hline $\begin{array}{l}\text { C4.15) Os tubos são armazenados em camadas, com os espaçadores, separadores segundo a bitola das peças } \\
\text { (NR 18) }\end{array}$ & & $\mathrm{x}$ & \\
\hline C4.16) Os tubos estocados estão em locais livres do sol, ou tem cobertura com a lona & & $\mathrm{x}$ & \\
\hline C5) PRODUÇÃO DE ARGAMASSA CONCRETO & $\mathrm{x}$ & & \\
\hline C5.1) A betoneira está localizada próxima ao guincho & & & $\mathrm{x}$ \\
\hline C5.2) A betoneira descarrega nos carrinhos diretamente & $\mathrm{x}$ & & \\
\hline C5.3) Há indicações do traço para produção de concreto, e as estão em local visível & & $\mathrm{x}$ & \\
\hline C5.4) A dosagem no cimento é realizada pelo peso & & $\mathrm{x}$ & \\
\hline C5.5) A dosagem na areia é realizada com equipamentos dosador & & $\mathrm{x}$ & \\
\hline C5.6) A dosagem d'água é realizada com equipamento dosador & & $\mathrm{x}$ & \\
\hline C5.7) A empresa possui uma central de concreto & & $\mathrm{x}$ & \\
\hline
\end{tabular}

Fonte: Dados da Pesquisa (2021).

Entre os 43 itens analisados em relação as instalações provisórias, 10 foram marcados com "SIM", representando 23,3\% do total, 14 itens não possuem no canteiro, o que significa 32,5\%, contudo apenas 19 itens não se aplicam ao canteiro, perfazendo um total de $44,2 \%$.

No quesito segurança na obra foram vistoriados 28 itens, apresentando que 7 encontram-se na categoria "SIM", representando $25 \%$ do total, 17 itens foram marcados "NÃO", representando 60,7\%, e 4 item foi marcado, não se aplicando ao canteiro, o que representou $14,3 \%$.

Para o sistema de movimentação e armazenamento foram analisados 38 itens, 15 foram assinalados como "SIM", o que representa 39,5\%, o "NÃO” foi assinalado 21 itens, que significa 55,3\%, e 2 item foi marcado, não se aplicando ao canteiro, o que representou $5,2 \%$.

O gráfico Comparativo para os três quesitos analisados (instalações provisórias, segurança na obra e movimentação e armazenamento) apresenta um comparativo das respostas da lista de verificações. 
Gráfico 1 - Gráfico Comparativo para os três quesitos analisados do Canteiro de Obras da Rodoviária Adilmar de P. Gadelha.

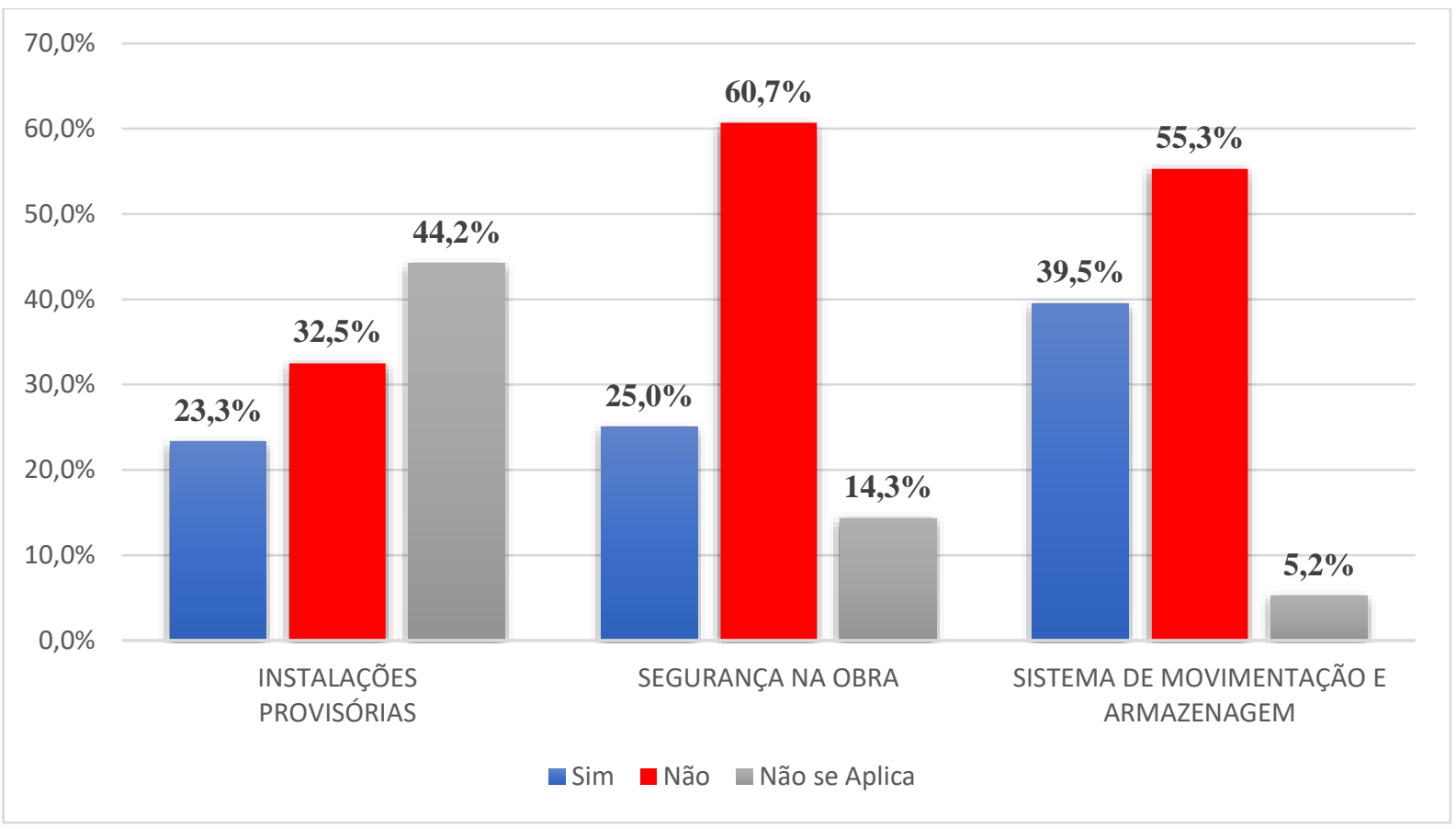

Fonte: Dados da Pesquisa (2021).

Conforme apresentado na lista de verificações, por seguir um modelo, apenas as instalações provisórias apresentaram um alto índice de não se aplica ou não possuem ao canteiro, pois cada modelo segue uma linha de construção, ou seja, verticais e horizontais, portanto parte da análise foi executada sobre o sistema de construção horizontal.

A segurança na obra conforme verificado no gráfico, foi o que apresentou maior porcentagens de itens que não possuem no canteiro. A segurança do trabalho é indispensável no canteiro de obras, visivelmente percebe-se a falta de treinamento dos funcionários treinados e falta de uso de EPI’s conforme as normas de segurança. Nesse aspecto, Leonardo e Brás (2013) relatam que a atividade profissional da construção civil está associada a riscos de acidente ou doenças profissionais, sendo obrigação de todo o empregador quantificar esse risco e tomar medidas para o minimizar.

A avaliação de riscos profissionais apresenta larga importância e deve ser base de sustentação das atividades de Segurança, Saúde e Higiene no Trabalho - SSHT. Estas, por sua vez, constituem, ao nível das empresas, um elemento determinante da prevenção de riscos profissionais e da promoção e vigilância da saúde dos trabalhadores (DECRETO LEI 26/94). A avaliação de riscos é da competência dos empregadores, sendo sua obrigação legal avaliar e informar sobre os riscos em que os trabalhadores incorrem no exercício das suas funções (DECRETO LEI nº 441/91). Assim, a avaliação de riscos profissionais apresenta-se como uma ferramenta fundamental para qualquer sistema de gestão da prevenção e de segurança no trabalho, permitindo que, após a identificação dos riscos existentes, se possam definir medidas de controle, eliminando ou reduzindo, para níveis aceitáveis, esses mesmos riscos. Contudo, qualquer avaliação está envolvida num processo de melhoria contínuo, ou seja, não é um processo estagnado, é algo revisto periodicamente para identificar riscos não previstos em revisões anteriores.

O sistema de movimentação e armazenagem é o segundo maior dos itens estudados que que não se tem no canteiro representando 55,3\%. Vale destacar que é necessária a existência de princípios que facilitem a implantação de melhorias nas atividades de movimentação e armazenagem em canteiros de obras com intuito de aumentar a produtividade e reduzir custos. Segundo Mota et al., (2012) essas mudanças podem diminuir o consumo de mão-de obra nas atividades de transporte não passam necessariamente por implantação de equipamentos sofisticados, podendo tomar medidas como: adoção de princípios básicos de economia dos movimentos; utilização de equipamentos adequados ao transporte; eliminação do desperdício de materiais. 
Gráfico 2 - Gráfico Comparativo de todos os itens do canteiro de obras da Rodoviária Adilmar de P. Gadelha.

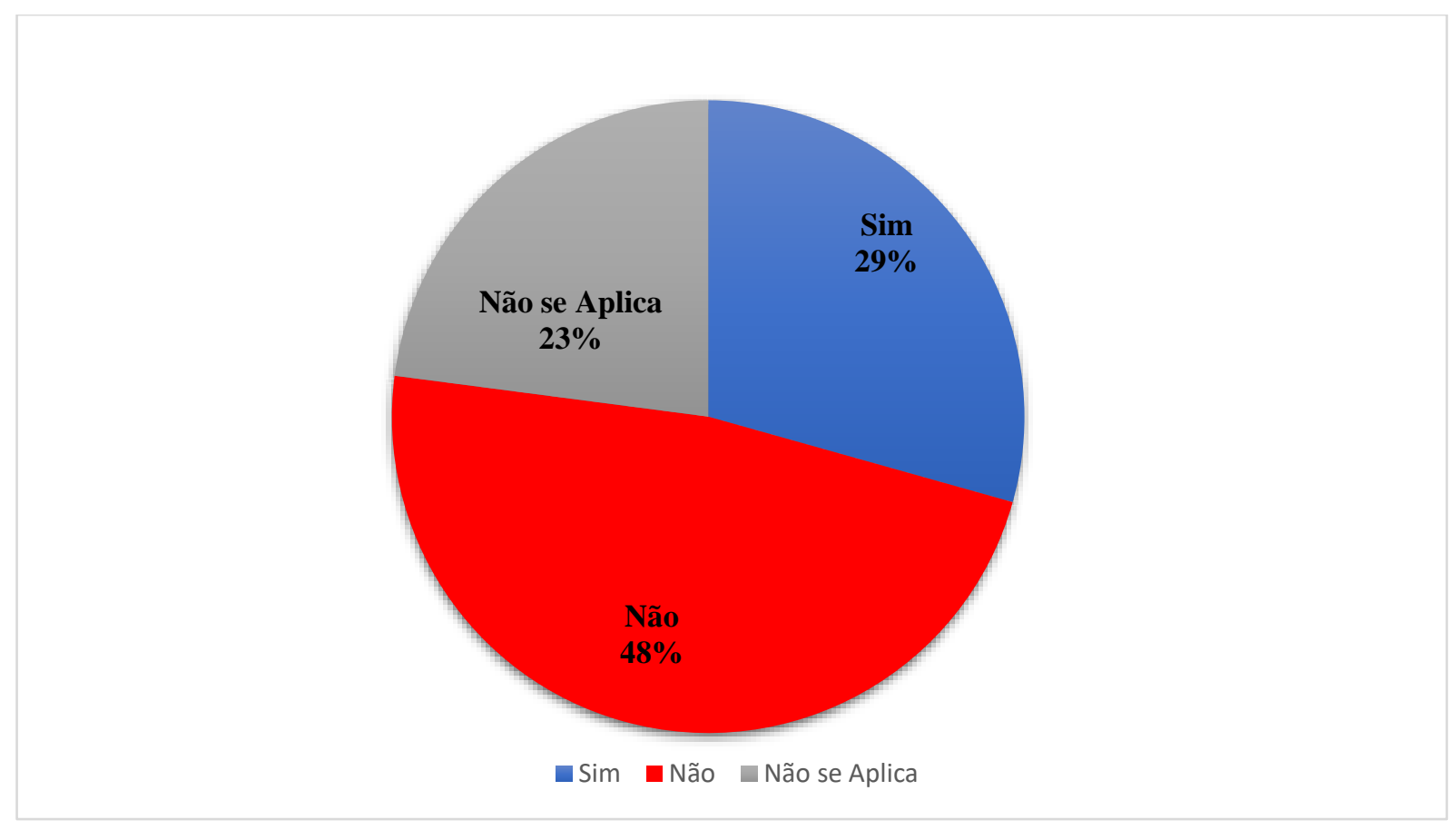

Fonte: Dados da Pesquisa (2021).

No geral pode-se notar uma alta porcentagem $48 \%$ de itens que não possuem no canteiro. De acordo com Amorin (2018) existe alguns componentes que são imprescindíveis no canteiro de obras, pois fazem parte das áreas de segurança e operacional, esses componentes independem do porte da obra e são dimensionados pelos engenheiros segundo as especificações da NR-18 e necessidade da obra. Os elementos do canteiro precisam atender todas as etapas da construção, desde a limpeza do local, passando pela execução da fundação até os detalhes final como o revestimento. É precioso considerar aspectos como a logística e segurança dos colaboradores.

\subsection{Principais Problemas Encontrados}

Os elementos do canteiro de obras podem ser aqueles que estão diretamente ligados com o processo de produção, por exemplo, os locais reservados no canteiro de obras para armação de ferragem/carpintaria ou também podendo estar ligados de maneira indireta dando o devido apoio a produção, assim a falta de organização ou planejamento pode ocasionar problemas especialmente no caso dos locais destinadas para estoque de materiais no interior do canteiro.

Deste modo, a armazenagem nada mais é do que uma totalidade das funções que tem nele a descarga, recepção, arrumação, carregamento, conservação de matérias-primas, produtos acabados ou semiacabados. Este processo envolve as mercadorias, e apenas produzira resultados quando é realizado com o objetivo de lhe acrescentar valor (DIAS, 2015).

Abaixo a Figura 3 mostra a desorganização e o armazenamento incorreto de alguns materiais. É possível observar baldes de tintas e massa corrida abertos, trazendo desperdício e prejuízo para a organização. 
Figura 3 - Armazenagem de incorreta de materiais no canteiro analisado.

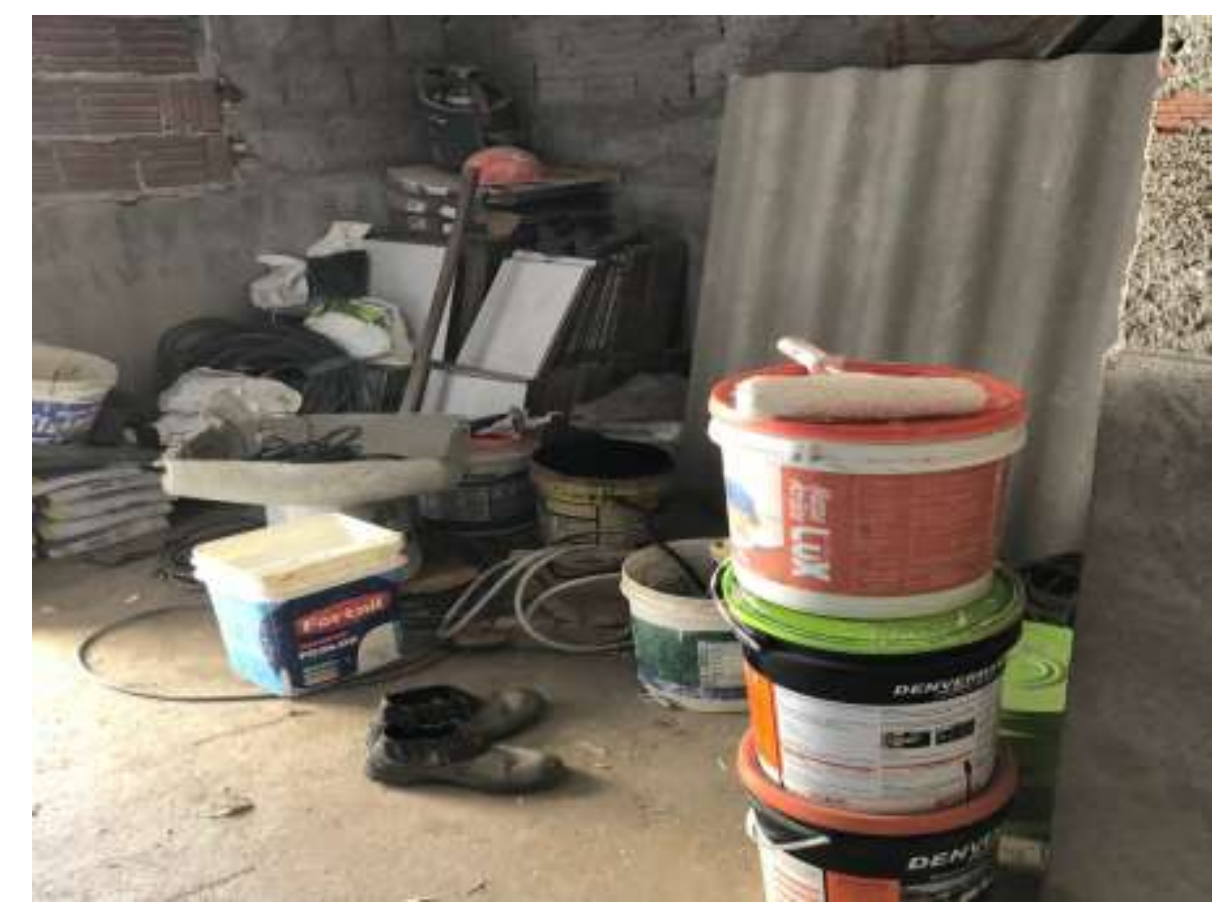

Fonte: Dados da Pesquisa (2021).

O almoxarifado tem as funções de armazenamento e de controle de materiais e das ferramentas, devendo idealmente situar-se próximo de três locais do canteiro, de acordo com a seguinte ordem: do ponto de descarga de caminhões, do elevador de carga e do escritório. No canteiro, o armazenamento de materiais/equipamentos é de importância primordial para evitar as perdas no processo. $\mathrm{O}$ armazenamento feito de maneira organizada e planejada, faz com que as equipes de produção, ganhem agilidade nos processos devido o material estar disposto de maneira sistemática, e localizada próxima as máquinas que houver necessitam para a produção (Araújo; Souza \& Silva, 2019).

No canteiro estudado, o almoxarifado fica longe do ponto de descarga de caminhões, além disso conforme figura 06 do armazenamento, os materiais estão totalmente desorganizados. De acordo com Araújo, Souza \& Silva (2019) a criação de depósitos para acomodação de materiais/produtos, deve ser realizada de maneira segura/organizada, evitado, assim o contado dos materiais com as intemperes do meio ambientes, tendo como finalidade de maximizar o rendimento do produto/material e evitar perdas desnecessária.

A falta de detalhamento é vista como um grande motivo da ineficiência de gestão em canteiro de obras, pois muitas vezes leva ao improviso na hora de executar determinados serviços. Se tratando de obras de engenharia, a "gambiarra" acaba gerando inúmeros transtornos, em que parte das vezes, é observada em etapas posteriores, levando aos inúmeros casos de patologias nas edificações.

Outro problema verificado foi a falta de segurança e higiene para com os trabalhadores como pode ser observado na figura 04. 
Figura 4 - Condições precárias do Banheiro usado pelos colaboradores no canteiro de Obras da Rodoviária Adilmar de P. Gadelha.

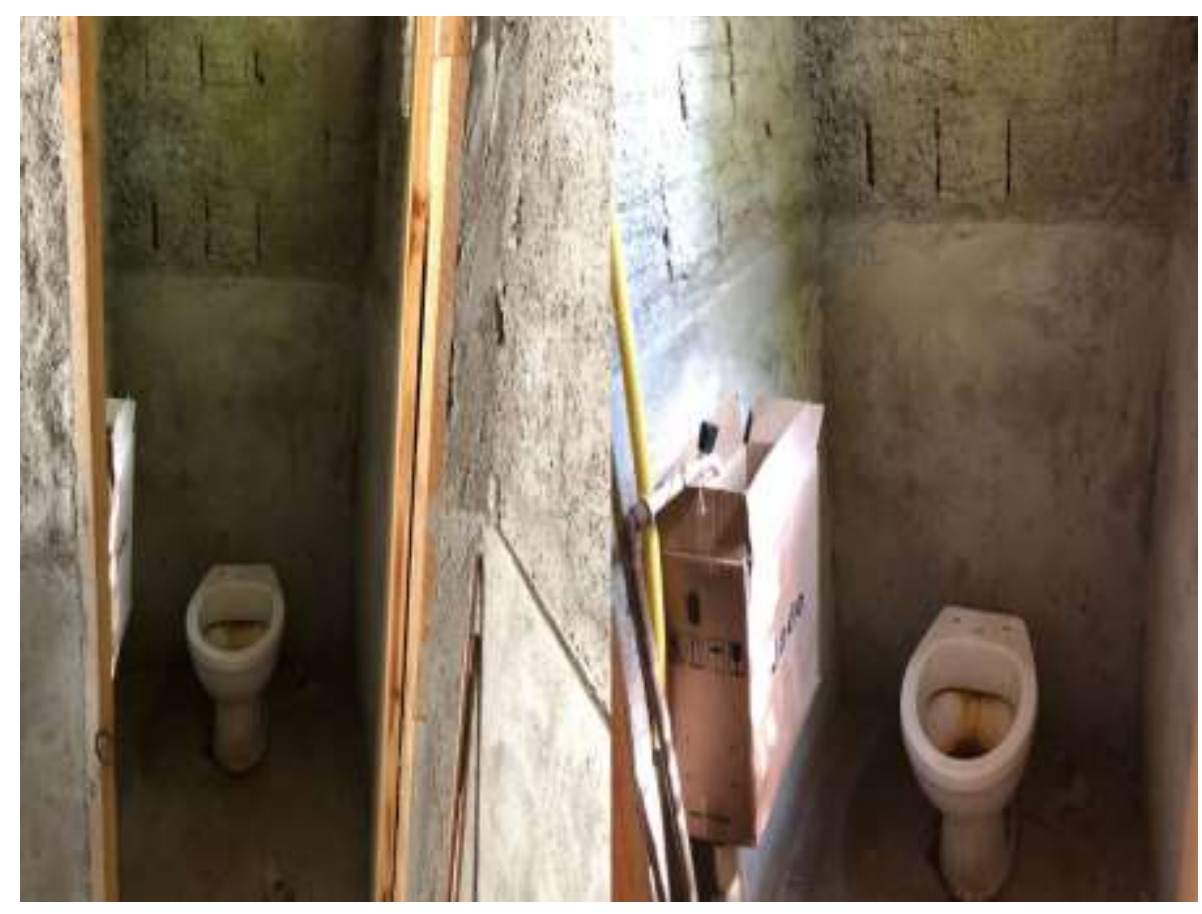

Fonte: Dados da Pesquisa (2021).

Como foi observado na figura 04 o banheiro está totalmente em desacordo com a NR-18, pois não possui descarga e a pia é uma caixa de papelão, trazendo diversos riscos aos colaboradores. Vale destacar que as instalações sanitárias precisam atender uma série de necessidades contidas na NR-18. De acordo com as definições da NR-18, as áreas como vestiário, refeitório, banheiros, área de lazer e alojamentos são áreas propostas a suprir as precisões básicas humanas de higiene, alimentação, descanso, convivência e lazer.

O bem-estar do trabalhador proporciona um ambiente de trabalho ajustado à sua tranquilidade, ou seja, agradável, amigável e, acima de tudo, produtivo. Hoje, as empresas sabem que é necessário se preocupar acima de tudo com o ser humano e não apenas com o trabalhador. É o trabalhador que está na organização para oferecer o que sabe, em contrapartida, ele espera também ser valorizado (Silva, 2011).

É uma via de mão dupla. Quanto mais a empresa investir, mais ela vai se beneficiar, pois o bem-estar do funcionário impacta grandemente em sua produtividade. Por isso que o investimento em qualidade de vida no trabalho só traz resultados positivos. Dar ao trabalhador um ambiente de trabalho seguro que se inicia com um salário justo, passa por uma jornada de trabalho compatível entre horas de descanso e horas trabalhadas, até a conscientização da importância e do seu valor na empresa, certamente a organização terá um trabalhador mais disposto, mais saudável e mais produtivo.

Por fim, destaca-se a acumulação de lixo e desorganização no almoxarifado, conforme Figura 5. 
Figura 5 - Lixo e desorganização no almoxarifado no canteiro de obras da analisado.

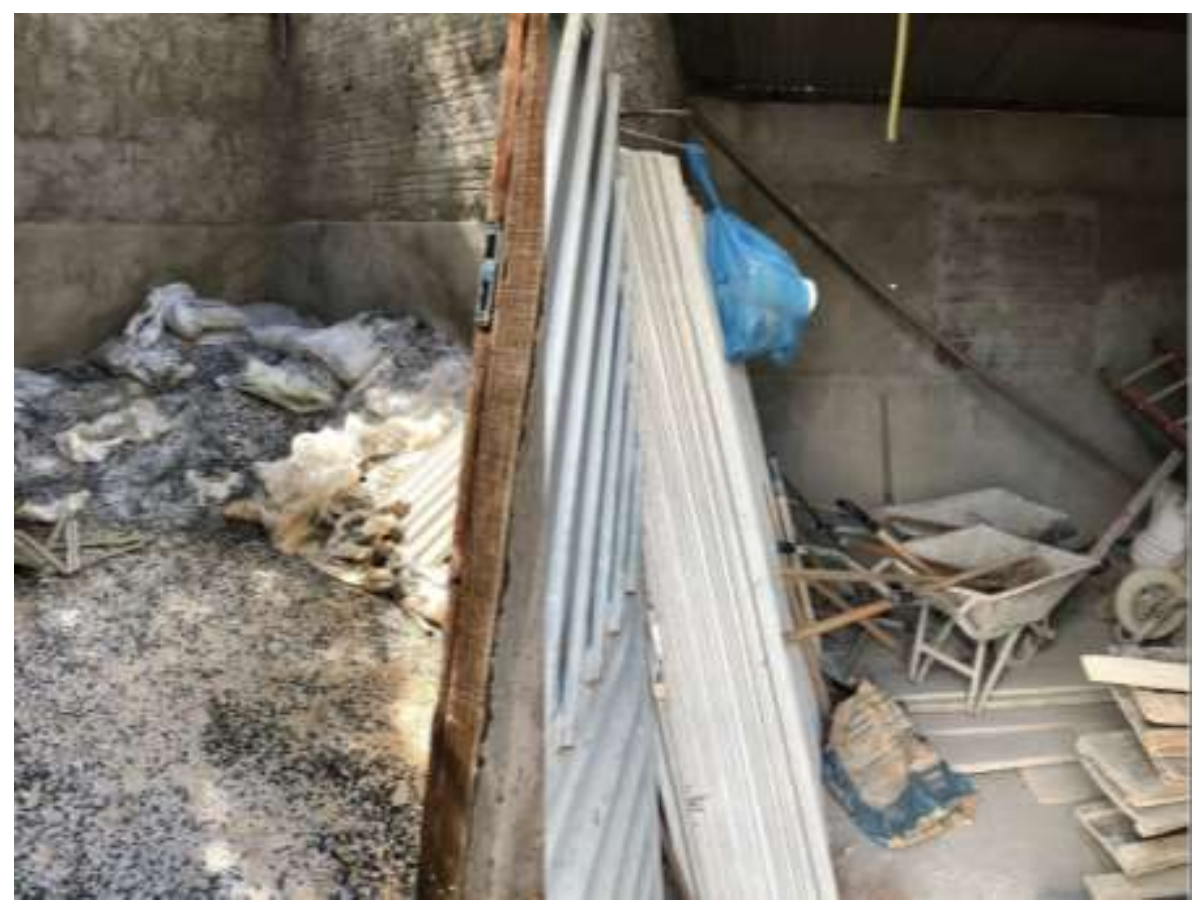

Fonte: Dados da Pesquisa (2021).

Alguns canteiros deixam a desejar em termos de saúde e qualidade de vida no trabalho. Fazendo com que colaboradores/clientes não tenham uma boa imagem da organização responsável.

Na figura 05 também é possível notar a presença de lixo, que para Portugal (2018) existem diversos tipos de problemas a partir do acúmulo de lixo que podem prejudicar ao meio ambiente. No entanto, um dos principais deles tem relação com os materiais utilizados nessas obras como: areia, concreto, cimento, massa, pedaços de cerâmica, vidro, ferro, tinta, entre outros, são alguns exemplos de materiais utilizados diariamente e em grande escala nesses locais. O pior de tudo é que alguns deles podem ser nocivos à natureza e descartados aos montes, todos misturados, fazendo com que haja a necessidade de usar várias caçambas de coleta por semana.

Embora o entulho sempre existe nas obras, em maior/menor quantidade, é necessário procedimentos adequados para armazenamento e transporte do mesmo. Em todo o processo construtivo existe a ocorrência de perdas associadas às atividades, o que deve ser evitado. São elevados os percentuais de desperdício por falta de planejamento na execução dos processos ou negligência dos principais responsáveis envolvidos.

Como sugestão de melhoria para esses problemas indica-se a utilização de um sistema de gestão da qualidade que promova uma abordagem com melhorias em toda a organização. O modelo proposto seria a metodologia 5 "S", que segundo Mello (2011, p. 146-148) significa:

1 - Seiri: “senso de utilização é separar o necessário o útil do desnecessário ou inútil.

2 - Seiton normalmente traduzido por "arrumação" o Seiton consiste em manter as coisas em seus devidos lugares de modo que possam ser facilmente localizadas sempre que necessário.

3 - Seiso que quer dizer "limpeza" significa manter o ambiente de trabalho e os equipamentos utilizados sem poeira sujeira ou resíduos de qualquer espécie.

4 - Seiketsu a manutenção da ordem da arrumação e da limpeza conquistadas nos três passos iniciais e a extensão de tais ações aos próprios funcionários são as palavras de ordem no quarto passo envolvendo a higiene em vários aspectos 
e a saúde do trabalhador.

5 - Shitsuke o quinto s por fim é a disciplina que está vinculada a fazer dos passos anteriores um hábito.

Além disso, a NR-06 é clara e estabelece as obrigações quanto ao uso do EPI, tanto ao empregador ao empregado. De acordo com Saliba (2004, p. 325), no subitem 6.6 da NR-06 ao empregador cabe:

a) adquirir o adequado ao risco de cada atividade;

b) exigir seu uso;

c) fornecer ao trabalhador somente o aprovado pelo órgão nacional competente em matéria de segurança e saúde do trabalho;

d) orientar e treinar o trabalhador sobre o uso adequado, guarda e conservação;

e) substituir imediatamente, quando danificado ou extraviado;

f) responsabilizar-se pela higienização e manutenção periódica;

g) comunicar ao Ministério do Trabalho e Emprego qualquer irregularidade observada.

O gerenciamento dos EPI's é substancial para o empregador, uma vez que há o controle sistemático dos equipamentos, especialmente aqueles que exigem a comprovação do uso efetivo em juízo e junto aos auditores-fiscais, como, por exemplo, protetores auriculares, respiradores, cremes de proteção, entre outros. É frequente o empregador ser condenado a pagar indenizações por falta de prova sobre o uso efetivo dos referidos EPI's. Assim, o dispositivo legal citado, além de outros, deve ser observado rigorosamente (Saliba, 2004).

Já com relação ao que cabe ao colaborador, NR-06 determina: a) usar, utilizando-o apenas para a finalidade a que se destina; b) responsabilizar-se pela guarda e conservação; c) comunicar ao empregador qualquer alteração que o torne impróprio para uso e d) cumprir as determinações do empregador sobre o uso adequado.

A orientação e treinamento dos empregados sobre o uso correto do EPI também devem ser comprovado, além disso, neste treinamento deve ser informado ao empregado a limitação e a importância do uso do EPI. Vale ressaltar, também que constitui ato faltoso do empregado a recusa injustificada de uso do EPI, fornecido pela empresa, conforme Art. 158, parágrafo único, alínea "b", da CLT, p. 326.

É imprescindível ter-se sempre em pensamento que a implantação de um bom planejamento é que determina a existência de uma ou outra situação. Por sua vez, a atividade de planejamento consome uma quantidade pequena de horas, não existindo, portanto, justificativas para a sua não realização, já que os recursos gastos são insignificantes frente aos benefícios que o mesmo resulta. Para obter um bom planejamento de canteiros de obras, é fundamental a observância de alguns procedimentos e diretrizes de planejamento, muitos dos quais apresentadas neste trabalho.

\section{Considerações Finais}

O canteiro de obra pesquisado pode ser classificado com resultados regular acerca das "Instalações Provisórias" e ruins na "Segurança", e "Movimentação e Armazenamento de materiais". Tais problemas detectados têm negativo impacto, principalmente nos processos produtivos, ao impedir que a organização melhore seus indicadores de produtividade e sua competitividade.

Pode-se ressaltar que o diagnóstico da produção pode ser um instrumento de motivação importante para o desenvolvimento de estratégias de produção em empresas de construção, principalmente quando elas não têm o hábito em discutir e explicitar estas estratégias. 
As vantagens de um planejamento do canteiro de obras são muitas, e por se tratar de um processo administrativo não eleva o custo do empreendimento, além do mais, quando executada de forma correta, facilita a produtividade, melhora o fluxo, assim como a lucratividade no final da obra.

O canteiro de obras estudado está sujeito a uma quantidade considerável de variáveis e necessita, para obter qualidade, de profissionais capazes de projetá-los de forma a prever maneiras de contornar as dificuldades a serem enfrentadas em cada fase da obra, impedindo que a qualidade produtiva seja perdida.

Dentre dos pontos a serem melhorados, os resultados mostraram a questão do lixo, armazenagem de maneira incorreta, a falta de uso de EPI e as questões relacionadas à segurança e saúde dos colaboradores. Desse modo, planejar e executar corretamente um canteiro é imprescindível para o acréscimo de produtividade em obras de construção civil. O planejamento cauteloso evita perdas, acidentes de trabalho e danos ambientais, gerando benefícios organizacionais, qualitativos e quantitativos, além de garantir uma maior produtividade.

Como sugestão de melhoria, recomenda-se a utilização de um sistema de gestão da qualidade que promova uma abordagem com melhorias em toda a organização. No cotidiano das organizações, existe um cuidado com todos os sistemas de gestão da qualidade total, sobretudo no que se refere ao processo produtivo, sendo este o foco de muitas organizações. Nessa perspectiva, indica-se a implantação dos 5 sensos, que é um conjunto de ferramentas usado para promover a qualidade nas organizações.

\section{Referências}

Altounian, C. S. (2012). Obras públicas: licitação, contratação, fiscalização e utilização. (3a ed.), Fórum.

Amorim, E. (2018). Análise do planejamento do canteiro de obras visando o processo produtivo: Estudo de caso. Trabalho de Conclusão de Curso (Engenharia Civil) apresentado a Universidade Regional do Noroeste do Estado do Rio Grande do Sul - UNIJUÍ.

Amorim, M. B., \& Rocha, A. C. B. (2012). Ferramentas de Engenharia de Produção para redução de desperdícios em cozinhas industriais. In: XXXII Encontro Nacional de Engenharia de Produção (Enegep): Bento Gonçalves.

Araújo, D. S., Souza, D. J. R. De., \& Silva, L. O. (2019). Planejamento e Gerenciamento do Canteiro de Obras. IV Colóquio Estadual de Pesquisa Multidisciplinar: II Congresso Nacional de Pesquisa Multidisciplinar, UNIFIMES.

Brasil. (1943). Consolidação das Leis do Trabalho (CLT). Senado Federal.

Brasil. (1994). Decreto Lei n. ${ }^{\circ}$ 441/91. D.R. n. ${ }^{\circ}$ 262, Série I-A de (1991-11-14). 5826-5833. Diário Oficial da União.

Brasil. (1978). Ministério do Trabalho e Emprego. NR-18: Condições e meio ambiente de trabalho na indústria da construção.

Custódio, T. B. C., \& Tomim, K. de S. (2016). Gerenciamento de tempo na execução de obras públicas no município de Assis Chateaubriand - PR. Trabalho de Conclusão de Curso (Engenharia Civil), Universidade Paraense - UNOPAR.

Dias, M. A. (2015). Administração de Materiais: Princípios Conceitos e Gestão. Atlas.

Gomes, R. L. (2015). Controle de processos produtivos em uma indústria de alimentos. Trabalho de conclusão de curso Trabalho de Conclusão de Curso (Curso de Graduação, em Engenharia de Produção), Universidade Tecnológica Federal do Paraná.

Hamzeh, F., Ballard, G., \& Tommelein, I. D. (2011). Rethinking lookahead planning to optimize construction workflow. Lean Construction Journal, 2(4), 1534.

Mattos, A. D. (2010). Planejamento e controle de obras. PINI.

Mello, C. H. P. (edit.). (2011). Gestão da qualidade. Pearson Education do Brasil.

Mota, G. R., Santos, M. V. A dos., Vieira, M. de M., Heineck, L. F., \& Oliveira, B. B. de. (2012). Princípios de movimentação e armazenagem na construção civil. XIV ENTAC - Encontro Nacional de Tecnologia do Ambiente Construído, 29 a 31 outubro, Juiz de Fora.

Perez, C. (2011). Proposta e implementação de um plano de qualidade para obras públicas de pequeno porte. 2011.181 f. Dissertação Mestrado (Engenharia Civil), Universidade Federal de Minas Gerais, Belo Horizonte.

Portugal, N. (2018). Reciclagem no canteiro de obras. Blog Catho Edu. https://www.catho.com.br/educacao/blog/reciclagem-no-canteiro-de-obras/.

Ribero, P. F. C. (2011). Caracterização dos Canteiros de Obras da Cidade de Angicos/RN. Trabalho de Conclusão de Curso (Ciência e Tecnologia) Universidade Federal Rural do Semi-Árido - UFERSA. 
Research, Society and Development, v. 10, n. 16, e23101623124, 2021

(CC BY 4.0) | ISSN 2525-3409 | DOI: http://dx.doi.org/10.33448/rsd-v10i16.23124

Romanel, F. B. (2017). Avaliação do processo de planejamento e controle da produção em obra de construção civil. Gest. Tecnol. Inov, 1(1).

Saliba, T. M. (2004). Curso Básico de segurança do trabalho e higiene ocupacional. LTr Editora.

Silva, M. S. T. C. (2011). Planejamento e Controle de Obras. Trabalho de Conclusão de Curso (Engenharia Civil), Escola Politécnica, Universidade Federal da Bahia.

Silveira Júnior, R., \& Gregório, R. (2015). Gerenciamento de contratos de obras públicas e seus indicadores da qualidade. XIX Exposição de Experiências Municipais em Saneamento, Poços de Caldas - MG.

Souza, H., \& Monteiro, A. (2011). Linha de Balanço uma nova abordagem ao planejamento e controlo na construção. In Anais do $2^{\circ}$ Fórum Internacional de Gestão da Construção: Porto. 